\title{
UNIVERSIDADE FEDERAL DO PARANÁ: UMA OPORTUNIDADE REAL DE CULTURA E ARTE
}

\author{
Federal University of Paraná: A real opportunity for culture and art
}

Patricia Guilhem de Salles Carvalho ${ }^{1}$

\begin{abstract}
RESUMO
O texto a seguir tem o propósito de contextualizar a relevância das atividades realizadas pela Coordenadoria de Cultura, reafirmando o princípio de indissociabilidade entre ensino, pesquisa e extensão tão presente na trajetória da Universidade Federal do Paraná, que em 2012, completou seu primeiro centenário. De uma forma bem sucinta e descritiva, o texto possibilita ainda, um maior entendimento sobre quais são os objetivos e as ações desenvolvidas por esta coordenadoria.
\end{abstract}

Palavras-chave: universidade; cultura; arte.

\section{ABSTRACT}

This paper intends to put in context the relevance of the activities performed by its Cultural Coordination, restating the principle of inseparability of teaching, extension and research always present in the history of Federal University of Paraná, which completed its hundredth anniversary in 2012. In a succinct and descriptive way, this text allows also a better understanding about the objectives and activities of the mentioned coordination.

Keywords:university; culture; art.

\section{Introdução}

A Universidade Federal do Paraná completou 100 anos: uma trajetória marcada pela evolução no ensino e na pesquisa. Durante este período, surgiram novos cursos, muitas disciplinas, fórmulas inovadoras e diferentes metodologias. A universidade cresceu. E entre tantas descobertas, reconhece a arte e a cultura como parte integrante da educação. Entende que tanto a arte como a cultura são essenciais para a formação humana e, através da Pró-Reitoria de Extensão e Cultura, cria uma política cultural. Surge então, em 1990, a Coordenadoria de Cultura, responsável por estabelecer ações e mecanismos que evidenciam as atividades artísticas, reforçando a importância do fazer e do pensar artístico dentro

\footnotetext{
${ }^{1}$ Mestre em Comunicação - Programa de Pós-Graduação em Comunicação da Universidade Federal do Paraná. Especialista em Gestão Pública. Graduada em Administração de Empresas (Faculdades Positivo) e Comunicação Social - Habilitação Publicidade e Propaganda (PUC-PR). Produtora Cultural na UFPR. E-mail: patricia.gsc@hotmail.com.
}

CARVALHO, Patrícia G. S. Universidade Federal do Paraná: uma oportunidade real de cultura e arte. Extensão em Foco, Curitiba: Editora da UFPR, nr.10, jul/dez 2014, p.109-116. ISSN 23587180. 
da universidade. A Coordenadoria de Cultura tem também o propósito de promover a troca de conhecimento com a comunidade, reafirmando o princípio de indissociabilidade entre ensino, pesquisa e extensão.

Atualmente, a Coordenadoria de Cultura conta com o Museu de Arte da UFPR(MUSA), o Teatro da Reitoria, o Teatro Experimental da UFPR (TEUNI)e seis grupos artísticos: Téssera Companhia de Dança, Orquestra Filarmônica, Coro, Madrigal, Grupo de MPB e a Companhia de Teatro Palavração. A participação nos grupos artísticos é aberta a alunos, técnico-administrativos, professores e pessoas da comunidade externa sem nenhum custo, o que configura uma possibilidade extremamente democrática no acesso à aprendizagem da linguagem artística, independente do vínculo com a universidade.

Cada grupo produz anualmente dois grandes espetáculos: uma temporada oficial no primeiro semestre e outra no final do ano. As apresentações são gratuitas e sempre acontecem nos espaços culturais da universidade. Os grupos também atendem demandas da comunidade interna e externa, apresentando-se em diversos lugares para um público bem heterogêneo, assumindo amplamente a função de pesquisa e difusão artística.

\section{Espaços culturais e grupos artísticos da UFPR}

\section{Museu de Arte da UFPR - MUSA}

Inaugurado em 2002, o Museu de Arte da UFPR foi criado para ser uma instituição museológica universitária dedicada à reflexão das artes virtuais.

As exposições, além do caráter artístico, têm o enfoque de formação acadêmica com a supervisão de professores universitários, reforçando a indissociabilidade entre ensino, pesquisa e extensão.

Parte do acervo artístico do MUSA é proveniente da antiga coleção da universidade, oriunda de uma política benéfica às artes entre as décadas de 50 e 60 . Outras obras vieram transferidas do Ministério da Educação (MEC), em virtude da desativação da sua representação em Curitiba. E um terceiro grupo foi adquirido em decorrência da política conduzida pela Pró-Reitoria de Extensão e Cultura, que obteve inestimáveis doações de artistas e colecionadores. 


\section{Teatro da Reitoria}

O Teatro da Reitoria é um importante marco da arquitetura modernista brasileira. Inaugurado em 17 de outubro de 1958, durante a Semana de Cultura, tem capacidade para 700 pessoas.

O teatro oferece uma intensa programação cultural à comunidade. São espetáculos, concertos e shows apresentados tanto pelos grupos artísticos da UFPR, como por importantes nomes do cenário cultural brasileiro. Além disso, também é palco para atividades oficiais da universidade como formaturas, simpósios, congressos, assembleias e aulas inaugurais.

\section{Teatro Experimental da UFPR - TEUNI}

O TEUNI foi criado segundo a concepção de teatro black-box para receber peças teatrais, espetáculos de dança, recitais de poesia, workshops, concertos de música erudita e mostras de cinema e vídeo.

Localizado dentro do prédio histórico da UFPR, este espaço cênico tem capacidade para 85 pessoas, dispostas em uma plateia móvel que pode ser adaptada a diferentes montagens artísticas.

\section{Téssera Companhia de Dança da UFPR}

Com uma história de inovação e excelência, a Téssera Companhia de Dança da UFPR completou em 2011 trinta anos de efetiva contribuição para o desenvolvimento da dança contemporânea no Paraná, conquistando o reconhecimento por suas atividades ininterruptas na produção de conhecimento, arte, extensão e cultura.

A fundamentação do seu trabalho coreográfico apóia-se nas diferentes linhas de pesquisa do movimento e do gesto significativo. Os bailarinos são preparados com a técnica da dança moderna, que busca na energia orgânica interpretativa a linguagem expressiva adequada às performances e aos processos de pesquisa e à construção das obras coreográficas.

Ao longo da sua trajetória, a Téssera Companhia de Dança da UFPR conquistou diversos prêmios nos mais prestigiados festivais de dança do país. 
Internacionalmente, participou da Bienal Internacional da Dança Contemporânea Universitária, na cidade de Lyon, França.

\section{Orquestra Filarmônica da UFPR}

Considerada a primeira orquestra de Curitiba e uma das primeiras do Paraná, a Orquestra Filarmônica da UFPR completa, no ano do centenário da universidade, 50 anos de atividades, desenvolvendo um trabalho que agrega a prática de orquestra com a execução de diversos repertórios da música erudita.

A iniciativa pioneira para o estabelecimento da Orquestra Filarmônica da UFPR como um conjunto de formação inicial deixou uma herança inestimável para a cultura paranaense. Entre seus ex-integrantes, há músicos profissionais atuando em orquestras da Europa, América do norte e de todo o Brasil. Por isso, desde 1962 ano da sua fundação - a orquestra busca dar oportunidade para que músicos iniciantes se desenvolvam, oferecendo a possibilidade da prática sinfônica.

\section{Coro da UFPR}

Fundado em 17 de outubro de 1958 por ocasião da inauguração do Teatro da Reitoria, o Coro da UFPR já realizou inúmeras apresentações pelo país e no exterior, interpretando grandes nomes da música erudita.

Desde 1988, o principal objetivo dos orientadores do Coro tem sido a formação individual do elenco, o que permite o acompanhamento mais sólido de cada cantor juntamente com o ensino e a pesquisa da técnica vocal, canto e interpretação.

O Coro da UFPR utiliza uma técnica de canto que prioriza as ressonâncias do corpo, selecionando-as em função do conteúdo das obras. Os integrantes se espalham por todo o local da apresentação criando uma experiência mais intensa para o público. Esta distribuição não tem um caráter cênico, e sim, um caráter de aproveitamento do espaço visando à relação do som com a acústica de cada ambiente.

\section{Madrigal da UFPR}

CARVALHO, Patrícia G. S. Universidade Federal do Paraná: uma oportunidade real de cultura e arte. Extensão em Foco, Curitiba: Editora da UFPR, nr.10, jul/dez 2014, p.109-116. ISSN 23587180. 
Formado por 21 cantores provenientes do Coro, o Madrigal torna-se oficialmente, em 2012, mais um grupo artístico da UFPR. Entretanto, desde 2010, o grupo já se reunia com o objetivo de aprimorar o estudo da técnica de canto erudito com uma metodologia de trabalho bem diferenciada: primeiro, os cantores estudam o repertório individualmente e, depois, realizam os ensaios em conjunto para a finalização da obra proposta.

O repertório adotado pelo Madrigal transita por vários períodos da história da música, desde o renascimento e barroco, até peças contemporâneas. A escolha das músicas é feita sempre com o propósito de explorar novas sonoridades e possibilidades de expressão da voz, privilegiando os estudos de acústica e sonometria em diferentes performances.

\section{Grupo de MPB da UFPR}

O grupo nasceu em 1994 quando alguns integrantes do Coro da UFPR se interessaram em cantar MPB. Desde então, tem como propósito pesquisar e difundir a música popular brasileira e, ao mesmo tempo, explorar e aprimorar as possibilidades da voz e do corpo como recurso artístico.

O Grupo de MPB da UFPR se destaca não só pelo seu repertório e qualidade artística, mas também pela criatividade da movimentação cênica em suas apresentações.

A preparação dos espetáculos temáticos é resultado de um intenso trabalho de pesquisa que inclui os mais diversos compositores, sem esquecer a evolução dos consagrados ritmos brasileiros.

\section{Companhia de Teatro Palavração da UFPR}

Fundada em 1996, a Companhia de Teatro Palavração da UFPR tem como objetivo a divulgação da linguagem teatral através da promoção de espetáculos, formação de atores e plateia.

Estudos e pesquisas fazem parte da rotina deste grupo que busca uma experiência além dos palcos. Os integrantes da companhia praticam exercícios de improvisação e criação de textos teatrais, e ainda desenvolvem trabalhos de produção, cenário, figurino, iluminação, sonoplastia e maquiagem. 
Desde sua estreia, a Companhia de Teatro Palavração da UFPR já apresentou diversas peças, entre adaptações, textos inéditos e montagens de grandes dramaturgos, atingindo sempre o propósito de fazer pesquisa e levar a linguagem do teatro aos mais diferentes públicos.

\section{Projetos sociais}

Outra preocupação da Coordenadoria de Cultura é promover ações que propiciem a inclusão social. Por isso, a universidade abre mais uma vez as suas portas para a comunidade, com o objetivo de proporcionar a jovens e crianças o aprendizado prático e teórico da dança e da música, assumindo a tarefa de contribuir com o desenvolvimento e aperfeiçoamento destes.

O convívio com a arte possibilita a estes alunos uma melhoria nos hábitos sociais, aumentando consideravelmente a comunicação verbal e corporal e, consequentemente, diminuindo fatores de inibição. Percebe-se também um aumento significativo da autoestima e do entrosamento entre o grupo social e familiar. Além disso, esta nova rotina sugere uma melhoria de hábitos relativos à organização pessoal como disciplina, horários, cumprimento de tarefas e compromissos préagendados. E o mais importante: o interesse em conhecer as diferentes áreas artísticas contagia os familiares elevando a cultura geral e o conhecimento artístico de toda a família.

\section{Curso de Dança Moderna da UFPR}

Ligado à Téssera Companhia de Dança da UFPR, o Curso de Dança Moderna foi criado em 1988 com o objetivo de oferecer ensino com qualidade, de forma democrática e gratuita para a comunidade.

Direcionado aos jovens, a partir de nove anos de idade, o curso desenvolve um trabalho de pesquisa, produção e transmissão de conhecimentos exclusivos da dança moderna, proporcionando o aprendizado prático da dança, com informações complementares de disciplinas teóricas, além da produção cultural e a divulgação da arte paranaense.

\section{Música para todos - programa de inclusão musical}

CARVALHO, Patrícia G. S. Universidade Federal do Paraná: uma oportunidade real de cultura e arte. Extensão em Foco, Curitiba: Editora da UFPR, nr.10, jul/dez 2014, p.109-116. ISSN 23587180. 
Vinculado ao Grupo de MPB da UFPR, o Música para Todos - Programa de Inclusão Musical - é um projeto que busca facilitar o ingresso de crianças e jovens, com idade entre sete e quatorze anos, ao mundo da música por meio da educação musical.

O trabalho é feito em duas etapas e tem a duração de dois anos. Na primeira fase, os participantes assistem às aulas de teoria musical, canto coral e têm as noções básicas sobre os instrumentos. Na segunda etapa, os alunos aprendem a técnica específica de um instrumento, que pode ser violino, violão, flauta doce, percussão ou piano. Em todos os ensaios são abordados exercícios de técnica vocal, relaxamento, concentração, percepção auditiva, coordenação motora, expressão corporal e ritmo.

\section{Festival de Inverno da UFPR}

A Coordenadoria de Cultura responde também pelo Festival de Inverno da UFPR, evento que acontece anualmente na cidade de Antonina (PR), sempre no mês de julho e é referência tanto para profissionais envolvidos com a produção artística, como para pessoas interessadas em iniciar-se nas artes.

Com vinte e duas edições ininterruptas, o Festival de Inverno propicia um espaço alternativo de aprendizagem prática, reflexão crítica, apreciação e produção artístico-cultural, diferente do acadêmico formal, numa verdadeira articulação entre ensino, pesquisa e extensão.

Além da grande importância do Festival de Inverno junto ao meio universitário, é importante ressaltar o seu envolvimento com a comunidade. programa tem se preocupado com o resgate do fazer artístico e do universo histórico local, assim como com o artesanato de toda região litorânea. A interação feita com a população por meio das oficinas e da recreação realizada em praça pública possibilita a presença contínua da universidade na cidade, numa política de integração e troca de conhecimento.

São ofertadas oficinas para crianças e adultos nas áreas de artes plásticas, artes cênicas, música, dança, literatura, comunicação, artesanato e educação especial.

CARVALHO, Patrícia G. S. Universidade Federal do Paraná: uma oportunidade real de cultura e arte. Extensão em Foco, Curitiba: Editora da UFPR, nr.10, jul/dez 2014, p.109-116. ISSN 23587180. 
O evento também oferece aproximadamente quarenta espetáculos, abrangendo as diversas linguagens artísticas como o teatro, a dança, e a música nos mais diferentes gêneros, do erudito ao popular. Todos de livre acesso.

\section{Considerações finais}

Todas as ações desenvolvidas pela Coordenadoria de Cultura, descritas acima, vem ao encontro de uma das missões da Universidade Federal do Paraná, conforme o Plano de Desenvolvimento Institucional (2012-2016, p. 07): "contribuir com o desenvolvimento sustentável, priorizando a formação continuada do profissional cidadão e produzindo, socializando e apropriando o conceito de forma articulada com os demais segmentos da Sociedade, sendo referência no Brasil.".

Desta forma, a Coordenadoria de Cultura assume o compromisso de investir na melhoria da qualidade de ensino da arte e na troca de experiências, servindo como elo de integração entre a comunidade e as mais variadas áreas artísticas.

\section{Referência}

UNIVERSIDADE FEDERAL DO PARANÁ. Pró-Reitoria de Planejamento, Orçamento e Finanças. Coordenadoria de Planejamento Institucional. Plano de Desenvolvimento Institucional 2012-1016. Curitiba: UFPR/PROLAN, 2012. 